\title{
CARACTERIZAÇÃO MECÂNICA DE MISTURAS SOLO-ESCÓRIA DE ALTO- FORNO GRANULADA MOÍDA PARA APLICAÇÕES EM ESTRADAS FLORESTAIS $^{1}$
}

\author{
Rodrigo Zorzal Velten ${ }^{2}$, Alexandre Pelissari Sant' Ana ${ }^{3}$, Dario Cardoso de Lima ${ }^{4}$, Cláudio Henrique de \\ Carvalho Silva ${ }^{4}$, Carlos Alexandre Braz de Carvalho ${ }^{4}$, Lauro Gontijo Couto ${ }^{4}$ e Carlos Cardoso Machado ${ }^{5}$
}

\begin{abstract}
RESUMO - O presente artigo objetivou avaliar a resistência mecânica de misturas solo-escória de alto-forno granulada moída e ativada com cal hidratada, para aplicações como camada de pavimentos de estradas florestais. O solo analisado é um residual jovem de gnaisse da Zona da Mata Norte de Minas Gerais, de textura arenosilto-argilosa, classificado como A-2-4 (0) pelo Sistema TRB e como NS' pela Metodologia MCT. A escória de alto-forno granulada moída empregada foi fornecida pela companhia brasileira Valemassa Indústria e Comércio de Argamassa Ltda. Utilizou-se uma cal hidratada comercial como agente ativador das reações de hidratação da escória. Trabalhou-se com teores de escória de 5, 10 e 15\%, em relação à massa de solo seco, e de cal hidratada de 5, 10 e 20\%, em relação à massa seca de escória. O estudo englobou a realização de ensaios de caracterização química da escória e de caracterização geotécnica do solo, bem como ensaios de compactação e de compressão não-confinada das misturas na energia de compactação do Proctor intermediário, considerandose os períodos de cura em câmara úmida de 1, 7 e 28 dias. Os resultados indicaram ganhos significativos de resistência mecânica das misturas com relação ao solo, observando-se aumentos expressivos na resistência mecânica, com aumentos nos teores de escória, cal e período de cura.
\end{abstract}

Palavras-chave: Estradas florestais, misturas solo-escória de alto-forno granulada moída e resistência mecânica.

\section{MECHANICAL CHARACTERIZATION OF SOIL AND GRANULATED BLAST FURNACE SLAG MIXTURES FOR FOREST ROAD APPLICATIONS}

\begin{abstract}
This paper addresses the evaluation of the mechanical strength of mixtures of a soil and a granulated blast furnace slag activated with hydrated lime for forest road engineering applications. The tested soil is a young residual gneiss soil classified as A-2-4 (O) by the TRB System and as NS' by the MCT Methodology. The slag was supplied by the Brazilian company Valemassa Indústria e Comércio de Argamassa Ltda. A commercial hydrated lime was used to activate slag hydration reactions. The laboratory testing program encompassed the following: geotechnical soil characterization; specimens prepared at slag contents of 5, 10 and $15 \%$ related to the soil dry mass, and lime contents of 5, 10 and $20 \%$ related to the dry slag mass; specimens compacted at the intermediate Proctor compaction effort; unconfined compression strength tests performed in specimens at the curing times of 1, 7 and 28 days. Data from the laboratory testing program supported significant increase in mechanical strength of mixtures when increasing slag and lime contents, as well as curing time.
\end{abstract}

Keywords: Forest roads, soil and granulated blast furnace slag mixtures and mechanical strength.

\footnotetext{
${ }^{1}$ Recebido em 30.03.2005 e aceito para publicação em 10.11.2005.

${ }^{2}$ Programa de Pós-Graduação em Engenharia Civil da Universidade Federal de Viçosa. E-mail: <rzorzal@ bol.com.br>.

${ }^{3}$ Furnas Centrais Elétricas S.A.

${ }^{4}$ Departamento de Engenharia Civil da UFV. E-mail: <declima@ufv.br>.

${ }^{5}$ Departamento de Engenharia Florestal da UFV. E-mail: <machado@ufv.br>.
} 


\section{INTRODUÇÃO}

Segundo a Associação Brasileira das Empresas Distribuidoras de Asfaltos (ABEDA, 2001), a malha rodoviária nacional apresenta uma extensão da ordem de $1.725 .000 \mathrm{~km}$, com aproximadamente $10 \%$ pavimentados; desse total, $83 \%$ enquadram-se na categoria de rodovias municipais e vicinais, dos quais $1,2 \%$ encontra-se pavimentado. Com relação ao setor florestal, Machado e Malinovski (1986) estimaram a extensão da malha viária em aproximadamente $600.000 \mathrm{~km}$.

Supondo que a grande parcela das rodovias em terra justifique os serviços de pavimentação ou outras melhorias que envolvam camadas do pavimento estabilizadas quimicamente, seja pelo número de veículos, seja pela importância regional e estratégica, provavelmente algumas centenas de milhares de quilômetros necessitarão ser pavimentados no médio e longo prazos, nos setores público e florestal do Brasil.

O presente trabalho insere-se em uma abordagem do emprego de resíduos industriais na melhoria do pavimento de estradas, em especial de estradas florestais. Nele, apresenta-se um estudo dirigido ao uso da escória de alto-forno em misturas com um solo para aplicação como camada de pavimento de estradas, abrindo-se um campo de interesse para estradas florestais que estejam inseridas nas áreas de atuação de companhias siderúrgicas.

\section{ESCÓRIA DE ALTO-FORNO}

A escória de alto-forno é um resíduo siderúrgico industrial constituído, basicamente, de aluminossilicatos cálcicos, como resultado da combinação da ganga do minério de ferro com as cinzas do coque e do calcário utilizado como fundente no processo siderúrgico da fabricação do ferro fundido ("ferro-gusa").

A composição química e o processo de resfriamento da escória de alto-forno são fatores determinantes na sua capacidade aglomerante. A escória, quando submetida a condições de resfriamento brusco na saída do alto-forno (processo chamado de granulação da escória), apresenta propriedades hidráulicas latentes (escória vítrea); mas, se o processo empregado for o contrário (resfriamento lento), a escória se cristaliza, formando-se um produto sem atividade hidráulica.

Assim, pode-se associar a reatividade da escória de alto-forno à sua forma de obtenção no estado vítreo.

R. Árvore, Viçosa-MG, v.30, n.2, p.235-240, 2006
Todavia, deve-se ressaltar que essa condição apenas não é suficiente para o seu emprego como aglomerante, pois é necessário que a escória seja solúvel, isto é, passível de ataque pela água, para que os elementos formadores dos compostos hidráulicos sejam liberados. Essa solubilidade é favorecida pelo teor de óxido de cálcio presente na escória. Dessa forma, a reação é lenta, mas, em meio fortemente alcalino ou através da ação de sulfatos ou de ambos, torna-se acelerada, sendo a velocidade de reação favorecida pela finura da escória (CINCOTTO et al., 1992).

\section{MATERIAL E MÉTODOS}

\subsection{Material}

\subsubsection{Solo}

Trabalhou-se com um solo residual jovem de gnaisse da Zona da Mata Norte de Minas Gerais. A amostra foi coletada no horizonte $\mathrm{C}$ de um talude de corte localizado na Vila Secundino, no Campus da Universidade Federal de Viçosa, na cidade de Viçosa.

\subsubsection{Escória de alto-forno granulada moída}

A escória de alto-forno granulada utilizada foi produzida pela empresa Aço Minas Gerais S. A. Açominas, com composição química apresentada no Quadro 1. Esse resíduo foi moído pela empresa Valemassa Indústria e Comércio de Argamassa Ltda., que forneceu uma amostra desse material para ser utilizada no presente trabalho.

Quadro 1 - Composição química da escória de alto-forno granulada moída

Table 1 -Chemical composition of the granulated blast furnace slag

\begin{tabular}{cc}
\hline Característica Química & Resultados $(\%)$ \\
\hline $\mathrm{SiO}_{2}$ & 34,3 \\
$\mathrm{Al}_{2} \mathrm{O}_{3}$ & 11,9 \\
$\mathrm{CaO}$ & 42,0 \\
$\mathrm{Fe}_{2} \mathrm{O}_{3}$ & 0,4 \\
$\mathrm{FeO}$ & 0,2 \\
$\mathrm{MgO}$ & 3,2 \\
$\mathrm{~K} \mathrm{O}$ & 0,7 \\
$\mathrm{Na}_{2} \mathrm{O}$ & 0,1 \\
$\mathrm{Mn}_{2} \mathrm{O}_{3}$ & 0,9 \\
$\mathrm{SO}_{3}$ & 0,03 \\
$\mathrm{~S}$ & 0,06 \\
\hline
\end{tabular}




\subsubsection{Cal hidratada}

Foi empregada uma cal hidratada comercial adquirida no comércio da cidade de Viçosa, Minas Gerais, da marca SUPERCAL e fabricada pela companhia ICAL. Sua função nas misturas foi atuar como elemento ativador das reações de hidratação dos compostos químicos da escória de alto-forno granulada moída.

\subsection{Métodos}

No presente estudo, trabalhou-se com: (i) caracterização geotécnica do solo e química da escória de alto-forno granulada moída; (ii) teores de escória de alto-forno granulada moída de 5, 10 e $15 \%$ em relação à massa seca de solo; (iii) teores de cal hidratada de 5,10 e $20 \%$ em relação à massa seca de escória; (iv) compactação de corpos-de-prova do solo e de suas misturas com escória de alto-forno e cal hidratada na energia do ensaio Proctor intermediário; (v) ensaios de compressão não-confinada realizados nos corposde-prova do solo e misturas compactados, nos períodos de cura de 1,7 e 28 dias.

Os ensaios foram realizados segundo as seguintes Normas Técnicas: granulometria (ABNT, 1984a), limites de Atterberg (ABNT, 1984bc), massa específica dos grãos (ABNT, 1984d), compactação (ABNT, 1986) e compressão não-confinada (DNER, 1994). Considerando que, presentemente, não se dispõe de norma técnica brasileira específica para a determinação da resistência mecânica das misturas em estudo, adotou-se aquela preconizada pelo extinto Departamento Nacional de Estradas de Rodagem (DNER, 1994) para a caracterização de misturas solo-cimento, envolvendo as etapas de compactação, cura, imersão em água e ruptura dos corpos-de-prova.

Quadro 2-Resultados dos ensaios de laboratório de caracterização geotécnica do solo

Table 2-Laboratory soil geotechnical characterization testing data

\begin{tabular}{lll}
\hline Parâmetros Geotécnicos & & Resultados \\
\hline & LL & 30 \\
Limites de & LP & 19 \\
Atterberg $(\%)$ & IP & 11 \\
\hline Peso específico dos & & \\
grãos $\left(\mathrm{kN} / \mathrm{m}^{3}\right)$ & $\gamma_{\mathrm{s}}$ & 26,15 \\
\hline & $<0,005$ & 8 \\
Granulometria $(\%)$ & $0,005=\%<0,05$ & 11 \\
& $0,05=\%<2,00$ & 81 \\
\hline Classificação & TRB & A-2-4 (0) \\
Geotécnica & MCT & NS' \\
\hline
\end{tabular}

\section{RESULTADOS E DISCUSSÃO}

No Quadro 2, apresentam-se os resultados dos ensaios de caracterização geotécnica realizados com o solo em estudo. Observa-se, nesse quadro, que o solo apresenta plasticidade relativamente baixa, com IP da ordem de $11 \%$ e textura areno-argilo-siltosa, sendo classificado como A-2-4 (0), segundo o sistema TRB, e como NS', segundo a Metodologia MCT.

No Quadro 3, mostram-se os resultados dos ensaios de compactação, englobando os parâmetros umidade ótima $\left(\mathrm{h}_{\mathrm{ot}}\right)$ e peso específico aparente seco máximo $\left(\gamma_{\mathrm{dmax}}\right)$ das misturas solo e escória, nas nove combinações de solo, escória de alto-forno granulada moída e cal hidratada consideradas no presente trabalho. Para fins práticos, observou-se que a adição de escória de altoforno granulada moída e cal hidratada aos solos não conduziu a variações significativas nos parâmetros ótimos de compactação.

Os Quadros 4, 5 e 6 trazem os resultados dos ensaios de resistência à compressão não confinada das misturas solo, escória de alto-forno granulada moída e cal realizados, respectivamente, nos períodos de cura de 1, 7 e 28 dias. Com relação aos dados apresentados nesses quadros, como já relatado por Sant'Ana et al. (2004), informa-se que as misturas com 5\% de escória ativada com 5 e $10 \%$ de cal hidratada e $10 \%$ de escória ativada com $5 \%$ de cal hidratada não resistiram à imersão em água por quatro horas nos ensaios de compressão axial realizados em corpos-de-prova cilíndricos segundo a metodologia recomendada pelo DNER(1994) para misturas solo-cimento, considerando-se os períodos de cura de 1, 7 e 28 dias.

Quadro 3 - Umidade ótima $\left(\mathrm{h}_{\mathrm{ot}}\right)$ e peso específico aparente seco máximo $\left(\gamma_{\mathrm{dmax}}\right)$ das misturas

Table 3 - Optimum moisture content $\left(h_{o t}\right)$ and maximum dry density $\left(\gamma_{\text {dmáx }}\right)$ of mixtures

\begin{tabular}{|c|c|c|c|}
\hline \multirow[t]{2}{*}{$\begin{array}{l}\text { \% Escória } \\
\text { de Alto-Forno } \\
\text { Granulada Moída }\end{array}$} & \multirow[t]{2}{*}{$\begin{array}{c}\% \text { Cal } \\
\text { Hidratada }\end{array}$} & \multicolumn{2}{|c|}{$\begin{array}{l}\text { Parâmetros Ótimos de } \\
\text { Compactação: Energia } \\
\text { do Ensaio Proctor } \\
\text { Intermediário } \\
\end{array}$} \\
\hline & & $\mathrm{h}_{\mathrm{ot}}(\%)$ & $\gamma_{\text {dmáx }}\left(\mathrm{kN} / \mathrm{m}^{3}\right)$ \\
\hline 5 & $\begin{array}{c}5 \\
10 \\
20\end{array}$ & $\begin{array}{l}13,14 \\
13,43 \\
13,80\end{array}$ & $\begin{array}{l}18,16 \\
18,09 \\
18,08\end{array}$ \\
\hline 10 & $\begin{array}{c}5 \\
10 \\
20 \\
\end{array}$ & $\begin{array}{l}13,25 \\
13,34 \\
13,29 \\
\end{array}$ & $\begin{array}{l}18,27 \\
18,20 \\
18,25 \\
\end{array}$ \\
\hline 15 & $\begin{array}{c}5 \\
10 \\
20 \\
\end{array}$ & $\begin{array}{l}13,52 \\
13,77 \\
13,41 \\
\end{array}$ & $\begin{array}{l}18,30 \\
18,21 \\
18,31 \\
\end{array}$ \\
\hline
\end{tabular}

R. Árvore, Viçosa-MG, v.30, n.2, p.235-240, 2006 
No presente trabalho, o mesmo comportamento foi, também, observado na mistura com $15 \%$ de escória ativada com $5 \%$ de cal hidratada, nos períodos de cura de 1 e 28 dias. Acredita-se que o desempenho dessa mistura aos sete dias de cura possa estar relacionado com possível desvio ocorrido no processo de compactação dos corpos-de-prova, embora se deva ressaltar que os valores de resistência à compressão não confinada, obtidos nesse período de cura (Quadro 5), são de pequena monta, da ordem daqueles associados às misturas com $5 \%$ de escória e $20 \%$ de cal e $10 \%$ de escória e $10 \%$ de cal, no primeiro dia de cura (Quadro 4).

Observa-se também, no Quadro 4, que, independentemente do período de cura considerado, aumentando os teores de escória e cal, aumentaram, significativamente, as resistências mecânicas das misturas, o que comprovou a ação positiva da escória, como agente estabilizante do solo analisado, e da cal, como agente de ativação de reações de hidratação da escória. Outro aspecto de interesse observado foi a influência positiva do período de cura nos ganhos significativos de resistência mecânica das misturas, observando-se o desenvolvimento de reações de cimentação com o tempo, como ilustra a Figura 1, com preponderância para os ganhos ocorridos nos primeiros sete dias de cura.

Considerando os teores de escória de alto-forno granulada moída e cal hidratada empregados no presente trabalho, bem como a recomendação da Norma Técnica NBR 12253 (ABNT, 1992) para misturas solo-cimento, que destaca que a resistência mínima dessas misturas deve ser igual ou superior a 2,1 MPa para um período de cura de sete dias, conclui-se que a mistura com $10 \%$ de escória ativada com $10 \%$ de cal praticamente atendeu às exigências de misturas solo-cimento para emprego como camadas de base e sub-base de pavimentos rodoviários.

Quadro 4 - Resultados dos ensaios de resistência à compressão não-confinada das misturas, no período de cura de um dia Table 4 - Unconfined compression testing data of mixtures for 1 day curing time

\begin{tabular}{|c|c|c|c|c|c|c|}
\hline \multirow[t]{3}{*}{$\%$ Escória } & \multirow{3}{*}{$\% \mathrm{Cal}$} & \multicolumn{5}{|c|}{ Tensão de Ruptura $(\mathrm{MPa})-1$ Dia de Cura } \\
\hline & & \multicolumn{3}{|c|}{ Corpo-de-Prova } & \multirow[t]{2}{*}{ Média } & \multirow[t]{2}{*}{ Desvio-Padrão } \\
\hline & & 1 & 2 & 3 & & \\
\hline \multirow{3}{*}{5} & 5 & 0,00 & 0,00 & 0,00 & 0,00 & 0,00 \\
\hline & 10 & 0,00 & 0,00 & 0,00 & 0,00 & 0,00 \\
\hline & 20 & 0,40 & 0,41 & 0,43 & 0,41 & 0,02 \\
\hline \multirow{3}{*}{10} & 5 & 0,00 & 0,00 & 0,00 & 0,00 & 0,00 \\
\hline & 10 & 0,47 & 0,43 & 0,49 & 0,46 & 0,03 \\
\hline & 20 & 1,78 & 1,75 & 1,75 & 1,76 & 0,02 \\
\hline \multirow{3}{*}{15} & 5 & 0,00 & 0,00 & 0,00 & 0,00 & 0,00 \\
\hline & 10 & 1,28 & 1,38 & 1,51 & 1,39 & 0,12 \\
\hline & 20 & 2,37 & 2,13 & 2,02 & 2,17 & 0,18 \\
\hline
\end{tabular}

Quadro 5 - Resultados dos ensaios de resistência à compressão não-confinada das misturas, para o período de cura de 7 dias Table 5 - Unconfined compression testing data of mixtures for 7 days curing time

\begin{tabular}{|c|c|c|c|c|c|c|}
\hline \multirow[t]{3}{*}{ \% Escória } & \multirow{3}{*}{$\% \mathrm{Cal}$} & \multicolumn{5}{|c|}{ Tensão de Ruptura (MPa) - 7 Dias de Cura } \\
\hline & & \multicolumn{3}{|c|}{ Corpo-de-Prova } & \multirow[t]{2}{*}{ Média } & \multirow[t]{2}{*}{ Desvio-Padrão } \\
\hline & & 1 & 2 & 3 & & \\
\hline \multirow{3}{*}{5} & 5 & 0,00 & 0,00 & 0,00 & 0,00 & 0,00 \\
\hline & 10 & 0,00 & 0,00 & 0,00 & 0,00 & 0,00 \\
\hline & 20 & 0,67 & 0,71 & 0,73 & 0,70 & 0,03 \\
\hline \multirow{3}{*}{10} & 5 & 0,00 & 0,00 & 0,00 & 0,00 & 0,00 \\
\hline & 10 & 1,97 & 2,02 & 2,11 & 2,03 & 0,07 \\
\hline & 20 & 4,47 & 4,42 & 3,97 & 4,29 & 0,28 \\
\hline \multirow{3}{*}{15} & 5 & 0,42 & 0,42 & 0,41 & 0,42 & 0,01 \\
\hline & 10 & 3,42 & 3,25 & 3,16 & 3,28 & 0,13 \\
\hline & 20 & 4,12 & 5,14 & 5,21 & 4,82 & 0,61 \\
\hline
\end{tabular}

R. Árvore, Viçosa-MG, v.30, n.2, p.235-240, 2006 
Quadro 6 - Resultados dos ensaios de resistência à compressão não-confinada das misturas, no período de cura de 28 dias Table 6 - Unconfined compression testing data of mixtures for 28 days curing time

\begin{tabular}{ccccccc}
\hline \multirow{2}{*}{ \% Escória } & \multicolumn{5}{c}{ Tensão de Ruptura (MPa) - 28 Dias de Cura } \\
\cline { 2 - 5 } & \multicolumn{3}{c}{ Cal } & \multicolumn{4}{c}{ Corpo-de-Prova } & Média & Desvio-Padrão \\
\cline { 2 - 5 } & 5 & 0,00 & 0,00 & 0,00 & 0,00 & 0,00 \\
5 & 10 & 0,00 & 0,00 & 0,00 & 0,00 & 0,00 \\
& 20 & 1,47 & 0,95 & 1,61 & 1,34 & 0,35 \\
\hline \multirow{3}{*}{10} & 5 & 0,00 & 0,00 & 0,00 & 0,00 & 0,00 \\
& 10 & 2,42 & 2,74 & 2,68 & 2,61 & 0,17 \\
& 20 & 5,42 & 5,56 & 5,38 & 5,45 & 0,09 \\
\hline \multirow{2}{*}{15} & 5 & 0,00 & 0,00 & 0,00 & 0,00 & 0,00 \\
& 10 & 5,85 & 5,32 & 5,19 & 5,45 & 0,35 \\
& 20 & $*$ & 7,12 & 6,94 & 7,03 & 0,13 \\
\hline
\end{tabular}

*corpo-de-prova danificado.

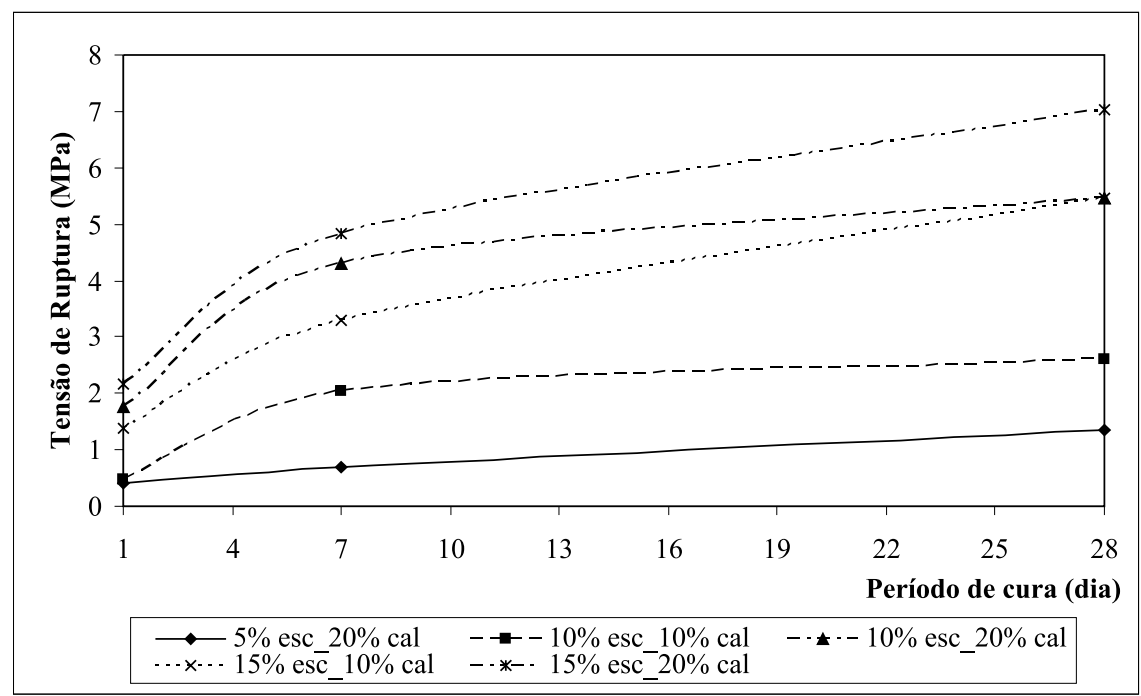

Figura 1 - Resistência à compressão não-confinada das misturas solo-escória de alto-forno granulada moída e com cal hidratada, nos períodos de cura de 1,7 e 28 dias.

Figure 1 - Unconfined compression strength of mixtures of soil, granulated blast furnace slag and hydrated lime for curing times of 1,7 and 28 days.

\section{CONCLUSÃO}

A análise dos resultados do programa experimental leva às seguintes conclusões: (i) a escória de altoforno granulada moída ativada com cal hidratada mostrouse um agente químico eficiente na estabilização do solo residual jovem em estudo; (ii) a adição de escória ao solo não causou variações significativas nos parâmetros ótimos de compactação desse solo; (ii) considerando-se o desvio-padrão observado, a mistura de $10 \%$ de escória ativada com $10 \%$ de cal atingiu aos sete dias de cura, para fins práticos, as exigências mínimas de resistência mecânica para o emprego de misturas solo-cimento como camadas de base de pavimentos rodoviários, segundo a NBR 12253.

\section{AGRADECIMENTOS}

Ao CNPq, pela concessão de bolsas de iniciação científica ao primeiro autor; à companhia Valemassa

R. Árvore, Viçosa-MG, v.30, n.2, p.235-240, 2006 
Indústria e Comércio de Argamassa Ltda., pelo fornecimento da escória de alto-forno granulada; e à Universidade Federal de Viçosa, pela infra-estrutura de laboratório e pessoal para a realização do presente trabalho.

\section{REFERÊNCIAS BIBLIOGRÁFICAS}

ASSOCIAÇÃO BRASILEIRA DAS EMPRESAS DISTRIBUIDORAS DE ASFALTO - ABEDA.

Manual básico de emulsões asfálticas: soluções para pavimentar sua cidade. Rio de Janeiro: 2001. 134p.

ASSOCIAÇÃO BRASILEIRA DE NORMAS TÉCNICAS - ABNT. NBR 7181/84, Solo Análise Granulométrica -

Procedimento. Rio de Janeiro: 1984a. 13p.

ASSOCIAÇÃO BRASILEIRA DE NORMAS TÉCNICAS - ABNT. NBR 6459/84, Solo Determinação do Limite de Liquidez - Procedimento. Rio de Janeiro: 1984b. 6p.

ASSOCIAÇÃO BRASILEIRA DE NORMAS TÉCNICAS - ABNT. NBR 7180/84, Solo Determinação do Limite de Plasticidade - Procedimento. Rio de Janeiro: 1984c. 3p.

ASSOCIAÇÃO BRASILEIRA DE NORMAS TÉCNICÁS - ABNT. NBR 6508/84, Solo Determinação da Massa Específica Aparente - Procedimento. Rio de Janeiro: 1984d. 8p.

R. Árvore, Viçosa-MG, v.30, n.2, p.235-240, 2006
ASSOCIAÇÃO BRASILEIRA DE NORMAS TÉCNICAS - ABNT. NBR 7182/84, Solo Ensaio de Compactação -

Procedimento. Rio de Janeiro: 1986. 10p.

ASSOCIAÇÃO BRASILEIRA DE NORMAS TÉCNICAS - ABNT. NBR 12253/92, Solo Cimento - Dosagem para Emprego como Camada de Pavimento. Rio de Janeiro: 1992. 7p.

CINCOTTO, M. A.; BATTAGIN, A. F.; AGOPYAN, V. Características da Escória

Granulada de Alto-Forno e seu

Emprego como Aglomerante e

Agregado. São Paulo: IPT, 1992. (Boletim, 65).

DEPARTAMENTO NACIONAL DE ESTRADAS DE RODAGEM - DNER. DNER-ME 201/

94, Solo-cimento - Compressão Axial de Corpos-de-prova Cilíndricos Método de Ensaio. Rio de Janeiro: Norma Rodoviária, 1994. 4p.

MACHADO, C. C.; MALINOVSKI, J. R. Rede viária florestal. Curitiba: FUPEF, 1986. 157p.

SANT'ANA, A. P. et al. Avaliação da resistência mecânica de misturas solo-escória de alto-forno granulada moída para fins rodoviários. In: SIMPÓSIO BRASILEIRO DE JOVENS GEOTÉCNICOS, 1., 2004, São Carlos. Simpósio... São Carlos: EESC/Universidade de São Paulo, 2004. 6p. (CD-ROM).

R. Arvore, Viçosa-MG, v.30, n.2, p.235-240, 2006 